\title{
FAVLAB II: digital fabrication in Favela da Maré, Rio de Janeiro
}

\author{
Verônica Natividade \\ PUC-Rio | Brazil | veronica.natividade@puc-rio.br \\ Carolina Cardoso \\ ISCTE-IUL | Portugal | a25425@iscte-iul.pt
}

\begin{abstract}
This article presents and discusses the result of a digital fabrication laboratory in a favela in Rio de Janeiro, Brazil. The laboratory is an experimental studio dedicated to teaching design and sharing technological knowledge between architecture students and young slum dwellers. The laboratory aims to explore collaborative design solutions for the public space in informal contexts, which meets local demands and presents an innovative and inclusive approach to digital design and fabrication. The paper offers a comprehensive theoretical background and the detailed methodology used in the studio.
\end{abstract}

Keywords: Collaborative design; Digital fabrication; Fab Labs; Favela; Education.

\section{INTRODUCTION}

Today, architects and urban designers have at their disposal a robust set of tools to describe complex realities, to understand social, economic, and spatial relationships (and to communicate them), which were ungraspable without the emergence of digital technologies. As digital literacy continuously pervades architecture and all fields of human knowledge in many positive manners, digital development also unveiled an alarming but controversial side. According to UNESCO's Chair Tim Unwin (Unwin, 2019), such technologies have dramatically increased inequality at all scales. In addition to increasing income concentration, digital technologies are triggering the unsettling social challenges from technological job displacement. How does the use of digital technology in architecture and urban design relate to this problem?

The past three decades of digital mastering tools granted architects extraordinary formal freedom and control over construction. The mass customization of non-repetitive building parts meant the triumph of individualization over modern universalization (Carpo, 2017). In contrast, as Modernist ideals of change by universal 'good' design failed miserably, architects gradually left behind major social aspirations. In contrast, this intentional detachment made architects increasingly irrelevant to society (Wisnik, 2018). Collaborative bottom-up approaches to the design process tuned to local demands emerge as crucial turning points to achieve the contemporary ambition of inclusiveness (Ermacora \& Bullivant, 2016). Although technology is a universal artefact, its application, questioning, and meaning must be local. Indeed, the recent coronavirus crisis led professionals worldwide to face the limits of work digitalization and production dependence on the physical world. It has also highlighted the relevance of adding value to local technologies and production at the expense of geographic concentration of production and technology (Rifkin, 211).
The present paper's central question is: how to make inclusive usage of digital tools in collaborative design processes in order to achieve local social impact? The theoretical background to support the argument that architects can resume their social relevance by using digital tools in an inclusive way and with local social impact is set upon four main concepts: (a) the contextual approach value in understanding technical developments and its social implications (Kranzberg, 1986); (b) citizenry activation by digital technology (Sassen apud Ratti, 2016); (c) the role of Fab Labs and (d) collaborative design and digital fabrication in slums' contexts (Natividade \& Dias, 2019).

This paper is twofold. It aims to explore the concepts of collaborative design under the digital technology realm and to discuss and share the results of the second edition of a digital fabrication lab in Favela da Maré, Rio de Janeiro. The lab is an experimental laboratory studio dedicated to teaching design and sharing technological knowledge among architecture students and young residents of poor areas. The laboratory aims to explore design solutions for public space in a favela in Rio de Janeiro that meets local demands. In this initiative, a broad spectrum of digital tools to meet collaborative methodologies was used. Those technologies included digital fabrication methods (3D printing, laser cutting, and CNC milling machine), Arduino, virtual reality, and parametric design.

In this way, this article intends to:

1. Contribute to the discussion on a more inclusive urban design, aiming at the transition to cities more adapted to the collective needs of the slum residents;

2. increase the involvement of citizens in co-creation strategies for their neighbourhoods through the appropriation and promotion of local technologies;

3. Contribute to the discussion about the transformation of the urban designers' role in the process of building cities of collaborative design, and; 
4. Address the digital technologies function in empowering and including different stakeholders in the collaborative design processes.

\section{THEORETICAL BACKGROUND \\ KRANZBERG'S LAW: LOCAL QUESTIONS TO GLOBAL TECHNOLOGY}

In the mid-80s', the technology historicist Melvin Kranzberg immortalized the sentence "technology is neither good nor bad; nor is it neutral," the first of six Kranzberg's Laws (1986). After thirty years of immersion in the study of technology developments and its interaction with the sociocultural change, Kranzberg rejected the assumption that "technology is pursued for its own sake and without regard to human need" (Ellul apud Kranzberg, 1986). On the contrary, Kranzberg summarizes his beliefs that human beings are the constituent elements of the technological process. The development of technology relies upon its interactions with culture and society as his sixth law states: "technology is a very human activity" (Kranzberg, 1986).

Throughout his paper, Kranzberg offers several examples to support his main argument that there is a profound relationship between social context and technological efficiency. In his fourth law, Kranzsberg affirms that "although technology might be a prime element in many public issues, nontechnical factors take precedence in technology-policy decisions." It means that technology does not always triumph over social and political forces; human components are key aspects to consider in applying certain technological developments in specific social contexts.

Although Kranzberg offers no specific examples in architecture or urban design, the author's point of view has dual importance in this work. The first is to support the idea that the digital technologies available in architecture can be more sensitive to local issues, focusing on the people and social aspects. The second is to reframe the notion and recalibrate the need for the technological transference between developed and developing countries. Despite the undeniable technical concentration in a few nations, particularly evident in the discrepancy in the budgets and equipment of architecture schools worldwide, the COVID19 crisis has reaffirmed the importance of economic and technological decentralization and enhancement of the search for local solutions.

\section{SASSEN: ACTIVATING THE CITIZENRY BY DIGITAL TECHNOLOGY}

Addressing digital fabrication in architecture and urbanism to local issues focusing on the human aspects led us to the sociologist Saskia Sassen's concept of citizenry activation by digital technologies (Sassen apud Ratti, 2016). Sassen brings Kranzberg's thinking to the urban design process when she states that "technology systems that might work in one city might not be desirable in another." For the researcher, technologies must be "urbanized" (Sassen, 2012), considering the local context in social, economic, political, and cultural aspects within a particular urban context.

Although Sassen focuses her digital technology to information processing and Big Data, she offers potent insights to value specific local wisdom and actions to produce tangible civic outcomes by 'leaking' the knowledge of the neighbourhood into codified systems in order to activate a citizenry (Sassen apud Ratti, 2013). Carlo Ratti (2016) calls it "hacking the city: opening traditionally closed information systems and breaking the ingrained mentality of optimized urbanism." The ultimate goal is to empower people to take an active role in their environment. The access to open-source technologies has a critical function to "aggregate knowledge, skills, and ideas from the broad and heterogeneous citizenry and actually make tangible changes" (Ratti, 2016). These are the seeds towards a "non-optimized city - one that embraces a touch of chaos and unexpected vitality" (Ratti, 2016).

For the present work, Sassen's reasoning is vital to set the tone on how to address technology in underprivileged urban areas in developing countries. Sassen invites us to question "what kinds of technological interventions might support the emergence of intelligence, subjects, and subjectivities, we would recognize as distinctly urban" (Greenfield, 2013) in such contexts, rather than replicate nominal solutions. How can we insert a robust conception of the right to the city in interventions that use digital technology in favelas, aiming to improve citizen involvement in local processes? And, finally, what alternative conceptions of digital fabrication technology applied in favela contexts can support the open and constantly changing character of these self-built territories with local intelligence, qualities often described as cunningness?

\section{FAB LABS}

In the crossbreeding of urban solutions and technology, prevalent technocentric approaches have turned the city into an "image of a technological urban utopia," raising criticism in the face of the dominant narrative of private companies by making technologies invisible, putting them in charge instead of dialoguing with citizens (Greenfield, 2013; Sassen, 2011). On the other hand, in recent years, there has been a growing increase in bottom-up initiatives that emerge from a collaborative approach and foster active citizenship. Such initiatives emerge as creative solutions that unleash experimental action. Rather than act as control instruments, in this context, digital technologies are the means to promote cooperation, engagement, and empowerment of citizens to act on complex urban problems (De Lange and De Waal, 2013; Concilio \& Rizzo, 2016).

The expansion of network connectivity has provided new, less hierarchical dynamics. Groups of people can connect and articulate themselves in local and global networks to organize around collective goals or issues (Castells, 2010). Inspired by the "wiki culture" (Ermacora and Bullivant, 2016) and the open-source movement, they have explored "the potential of communication networks to promote the dissemination of free knowledge" (Sá, 2015). The concept of openness, popularized in the 90 s and 2000 s, allied to the growing tendency for individuals and groups to build things on their own have spread the do-it-yourself (DIY) movement in the contemporary world. Its most recent evolution, "do it with others" (DIWO), is related to the importance of sharing (Garret, 2012), from which people from a different area, globally-connected or both, can develop solutions together with and for open communities from design to materialization. This scenario has contributed to the reflection on the transformed role for 
architects and urban planners in building cities of collaborative design.

The increasingly widespread access to digital manufacturing tools - such as 3D printers, CNC milling machines, and laser cutters - allied to the diffusion of sharing platforms, granted the DIY and DIWO movements other opportunities and challenges that open up a myriad of new possibilities for collaboration. Merging the software and hardware frontier, with subtractive CNC machines (computer-aided machines for cutting, drilling, and notching) and additive 3D printers, it is possible to easily transform the digital code into a physical object, allowing greater personalization and customization in the production of things (Claudel \& Ratti, 2016; Gershenfeld, 2005). Free access to an open-source design enables us to envision a particular project that can be modified and adapted by several subjects from a collaborative perspective. Thus, "contributing to the expansion of knowledge on a specific problem and enabling new approaches for its solution" (Hummels, 2009 in Pacheco \& Sperling), unleashing new modes of collaboration between different actors.

In this front of different movements that are interconnected towards a digital collaboration in the design processes, a growing worldwide network of experimental laboratories emerges, among which, the well-known Fab Labs - digital fabrication laboratories - originating from the Massachusetts Institute of Technology (MIT) and that quickly expanded around the world.

In a brief historical review, the first laboratory known as Fab Lab was implemented in 2003, within the Center for Bits and Atoms (CBA), and funded by the National Science Foundation (NSF). Originating in a discipline called "How to make (almost) anything," taught by professor Neil Gershenfeld and director of CBA, it emerges within the intention to teach students from different areas the possibilities of digital and personal manufacturing to respond to different needs (Gershenfeld, 2012; Eychenne \& Neves 2013). In the same year, the CBA team, led by Sherry Lassiter, created the first Fab Lab for the Boston urban community at the South End Technology Center, a CBA educational extension project. A year later, the second extension project was implemented in Ghana with NSF support (Gershenfeld, 2012). In 2020, there are more than 1000 active labs registered in Fab Foundation, with different operation models (academic, professional, or social), "spread from inner-city Boston to rural India, from South Africa to the North of Norway" (Diez, 2012). Despite the network's diversity, MIT tries to maintain some agency control under the terms of the 'fab charter,' which is a list of rules to be followed by Fab Labs. These rules include a few obligations, such as: being open to the public; allowing the democratization of technology and knowledge; having a standard set of digital manufacturing tools; allowing their replicability anywhere in the world; and active participation in the network (CBA, 2012; Fab Foundation, 2019).

In this work, Fab Labs emerge at the crossroads of the search for implying local meanings for digital manufacturing technologies, always keeping in mind the human and social value of the technologies and the search for valuing

https://likemyplace.wordpress.com/2014/02/10/digitarchite cture-digital-slum-by-iaac-barcelona-2010/ emerging subjects and intelligence through urban systems hacking and open-source technologies. Fab Labs were created to function as a place for learning and innovation. As such, Fab Las are environments that promote processes of bottom-up innovation and education based on "learning by doing," through access to digital manufacturing machines and knowledge derived from digital networks, enabling anyone to produce their projects. Thus, these laboratories intend to grant access to a highly specialized technological environment that provides skills, materials, and advanced technology to empower its members' ability to build local, sustainable community-based solutions using open-source tools and digital fabrication technology. According to Gershenfeld (2017), in addition to promoting innovation, Fab Labs also allows the quick creation and test of low-cost products within the community, taking advantage of the suggested improvements that will help these solutions evolve collaboratively.

\section{DIGITAL FABRICATION IN FAVELA CONTEXT}

In complex environments regarding social, political, and economic aspects such as favelas, collaborative spaces like Fab Labs "can play an influential role in providing knowledge tuned in to worldwide technological updates and access to productive means" (Natividade \& Dias, 2019). In such contexts, Fab Labs can breed new solutions to start re-establishing the balance between luminous and opaque territories in developing countries' communities. They may also offer an educational component of digital manufacturing awareness that favours the democratization of technological concepts and techniques. Fab Labs in favelas can also function as incubators of local innovation enterprises, and as decisive alternatives for those who abandoned formal education (Natividade \& Dias, 2019).

It is crucial, however, to assume a critical position when importing developed countries' technological models into the developing countries' reality "due to their asymmetric levels of socioeconomic, scientific, and technical development" (Natividade \& Dias, 2019). Especially when it comes to slums or underprivileged urban areas, Kranzberg (1986) and Sassen $(2011,2012,2013)$ provide us with important broader conceptual keys to set the approach tone. Additional relevant references are provided by the Digital Slum project and the FabCity model, both proposed by Tomas Diez (2012). In these two examples, Diez exposes in practical terms how the same tool that has been used to construct spectacular sculptures can be reoriented to offer solutions to local problems.

The Digital Slum Project ${ }^{1}$ was developed within a cooperation between the Institute for Advanced Architecture of Catalonia (IAAC) and the Central University of Venezuela (UCV) during the IAAC Summer School workshop, held in August 2010. The proposal was embedded in the IAAC and Fab Lab Barcelona's agenda of addressing informalism. The informalism agenda aims to study, analyze, and intervene in non-formal aspects of the City. That is, those self-generated processes and selfproduced by emerging forces in critical moments and needs. This workshop focused on empowering the forces engaged in the production of a specific reality. It also aimed 
to provide access to digital fabrication advanced tools to promote development through a renewed approach to selffabrication in light of mixing low-tech and high tech means for the intervention of the private and public space. The prototype outcome considered the self-fabrication principles of slums. The digitally fabricated structure reflects "the relation between the low technology in informal areas and the high technology in the Fab Labs" (Diez, 2012). It was developed by forty students from UCV in three weeks and intended to be constructed in Petare (Caracas), one of the largest slums in Latin America.

The FabCity ${ }^{2}$ aims to become a new model for the city, which aims to provide a renewed social, economic, and productive dimension to digital fabrication tools by redefining the use of new information technologies and production. The model suggests a synergic collaboration between citizens, FabLabs, and city officials in order to implement new local urban models through interventions in governance and policy. In the FabCity framework, platforms such as Fab Labs act as productive and talentattracting centres, capable of dealing with the realities of ordinary people, but at the same time connecting to a metropolitan and global network of knowledge related to the use of technologies of digital fabrication (Diez, 2012). The model relies on "the power of giving back to the cities the ability to produce through micro-factories inserted in the urban fabric and connected to the citizens" (Diez, 2012). Instead of building the cities in conventional terms, FabCity aspires to prototype the city by engaging in site-specific action-research and deploying strategies across localities in our network.

Despite the fact that the FabCity model has been initially designed for Barcelona, the FabCity Global initiative network is spread worldwide. Indeed, an influential example for the present work that merges this paper's main four concepts - the social feature of technology; citizenry engagement; Fab Labs and digital fabrication in slums comes from Brazil: the Laboratory CEU ${ }^{3}$ New World Territory (LABCEU).

LABCEU started in 2014 as a pilot project in the Favela Vila Maria, in the city of São Paulo and it was an initiative promoted by the Municipal Secretary for Urban Development (SMDU) ${ }^{4}$. The project proposed to carry out a series of activities with the local community for two weeks in order to map the needs, desires and expectations of Villa Maria residents for the new CEU that would be built in the region. The objective was to ensure the resident's participation in designing and implementing that public equipment. They also participated in the decision-making process to define which activities CEU should carry out. Through an itinerant wagon - the Labmóvel ${ }^{5}$ - equipped with technological resources, activities were carried out in the public space of the community. Art-educators headed a collaborative mapping of visible and invisible elements and individual and collective narratives as a means to get to know the neighbourhood and its shared values deeply.

\footnotetext{
${ }^{2}$ For more information about the project: https://fab.city/

3 Unified Educational Centers (CEUs) are public educational facilities. For more information: https://educacao.sme.prefeitura.sp.gov.br/centros-educacionaisunificados-ceus/
}

In addition to the itinerant wagon, the project also established a partnership with Garagem Fab Lab to produce a digitally manufactured model that served as the basis for mapping activities. The collective mapping over the neighbourhood physical model also enabled daily readings of the territory by different groups involved, adding new layers to local comprehension. One powerful strategy was taking the $3 \mathrm{D}$ printer to the favela because it caught the dwellers immediate attention, especially among the youngest, working as a listening tool. As a result, the proximity to such an intriguing technology motivated them to participate in activities. In practical terms, it allowed the almost instantaneous insertion of new elements to the collaborative physical model.

Resident children were also included in ludic-pedagogical activities. Children were asked to design their favourite meeting places - such as the neighbourhood pizzeria - or to point out their recurring activities - such as the launching kites. Then, a 3D printing workshop was held in the public space, when children could see their drawings materialized and introduced in the model. Besides the fascination that $3 \mathrm{D}$ printing may cause in children, the goal achieved here was to guarantee children's inclusiveness in public space production, which is very rare.

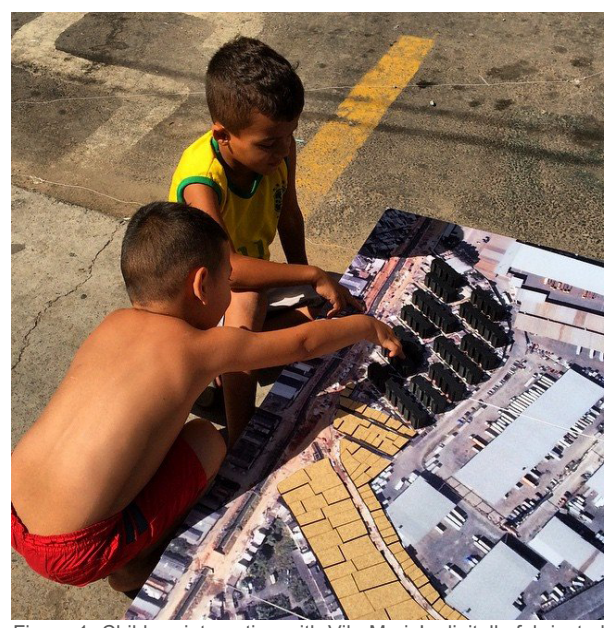

Figure 1: Children interacting with Vila Maria's digitally fabricated model.

The last example to complete this paper's theoretical background is the FavLab Maré Edition workshop (Natividade \& Dias, 2019), also held in Brazil. Although this is not a Fab Lab formally speaking, the name FavLab is directly related to that global network of digital fabrication laboratories. The FavLab was created in Rio de Janeiro as a way to connect the formal academic processes with the inventiveness of favelas through digital design and fabrication. The workshop experience has evolved into a current partnership between PUC-Rio University and IMJA 
(Instituto Maria e João Aleixo) located inside the slum Favela da Maré.

The FavLab Maré Edition workshop aimed to create and fabricate meaningful objects for the favela, exploiting digital design, and fabrication methods (Natividade \& Dias, 2019). Differently from the LABCEU workshop, FavLab had a studio format, and it was addressed to architecture undergraduates and local young residents that held some digital technologies' background. This heterogeneous group of students worked together to design and construct meaningful objects for the favela's public space. The workshop's core concept was 'adaptation', "whether in sitespecific and parametric variation design approaches or in adapting possibilities of digital design and fabrication to local conditions" (Natividade \& Dias, 2019). On this note, one exceptionally provocative remark of this experience relies on the shifted and singular use of parametric design: "the final location of construction could not be previously settled because it depended on negotiations between local leaders and other actors, such as armed civilians. So, parametric design played an essential role in fitting the proposals to any context" (Natividade \& Dias, 2019).

The workshop outcome was an interactive light installation for children activated by the voice. It consisted of a series of interlaced pipes equipped with sound sensors connected to an Arduino board that would control turn on the led light stripes inside the pipes. Students came up with a mix of digital and analogue manufacturing processes to gather the installation. They also set up sensors, programming behaviour, and electronic circuits. The concept behind this ludic toy was to give voice to the community's residents, especially the children: "the statement behind the funny game was making it evident that all voices are powerful, that all voices can and should be heard" (Natividade \& Dias, 2019).

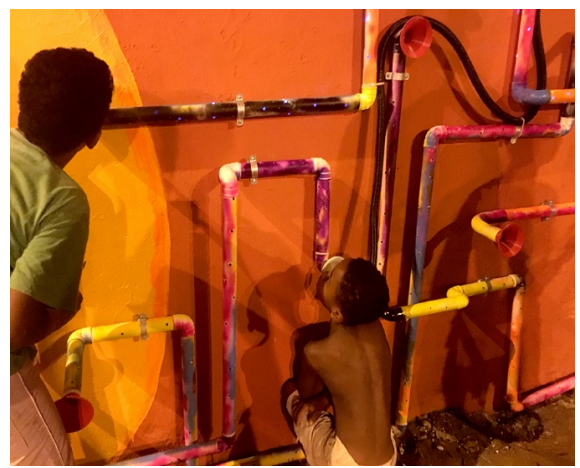

Figure 2: Kids testing FavLab's workshop outcome.

The examples examined here reflect the importance of promoting the use of technology as a tool for cooperation in collaborative processes in informal contexts. These precedents of an inclusive approach to digital design and fabrication set a stage where technology as a means and not an end in itself. "The fusion of suitable technologies with access to productive digital processes opens up a myriad of possibilities regarding participatory design. It also implies new meanings to digital design in social terms" (Natividade \& Dias, 2019).

\section{FABLAB MARÉ II WORKSHOP: BRINGING TO ACTION}

In this section, we will describe a digital design and fabrication workshop to produce objects for the public space of a favela in Rio de Janeiro, in the lights of the concepts and examples analyzed in this paper. The workshop involved the architecture school and the sociology department of PUC-Rio, the ICTE Lisbon Technology and Architecture School (ISTA), the NYU researcher Marcella del Signore, and the IMJA institute in Favela da Maré. The workshop was held in February 2020 and ran partially in the favela and partly in the university. The workshop was offered for seven architecture students from PUC-Rio and seven young favela residents selected by IMJA. The equal students' number from each institution was an important measure to keep balance and representation.

\section{METHODOLOGY}

The workshop methodology integrated five phases, as described below: (1) territory recognition, (2) technological knowledge sharing; (3) co-design, (4) co-production (5) and implementation, systematized in the scheme shown in Figure 3 .

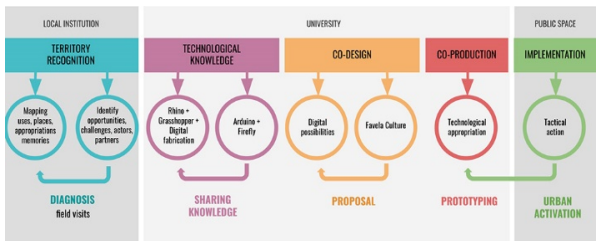

Figure 3: Methodology scheme

The workshop included a theoretical and a practical section. The studio offered three thematic masterclasses: (1) Urban Anthropology; (2) Experimental urban laboratories and participatory tools; and (3) An overview of digital processes in design and manufacturing. The goal was to introduce concepts, methodologies, and tools that would assist the participants in the collaboration process for the proposals' development. The lectures were structured according to three key topics: 'CHALLENGES', 'CONCEPTS', and 'TOOLS'.

After each masterclass, students received a set of cards that related the topics to each presented concepts. The cards set had a triple function: to help students navigate through newly introduced concepts, help participants in relating objective and subjective perceptions in the context of the territory at study, and structure daily collective thinking by facilitating communication between the different actors involved. After each masterclass, students were stimulated to discuss and share their particular views and experiences regarding the themes. Discussions between researchers, architecture students, and residents who participated in the laboratory contributed to formulating a critical reflection on the socio-territorial reality. This process enabled students to collectively identify opportunities and challenges that could lead to a tactical action in the territory that was relevant to the population and to identify which tool would be the most appropriate to achieve the goals. 
Phase I - Territory recognition

(days 1 and 2)

In the first two days, the studio took place in the favela. The workshop was initiated with the masterclass (1) Urban Anthropology, which covered the issues of collective memory, spatial appropriation, concepts of space and place, the dialectics of programmed space versus spontaneously created spaces, and the formation history of that particular slum. Within this lecture, the tools offered to students included observation in loco, mapping, interviews, commented field trips, photographs, and registering drawings

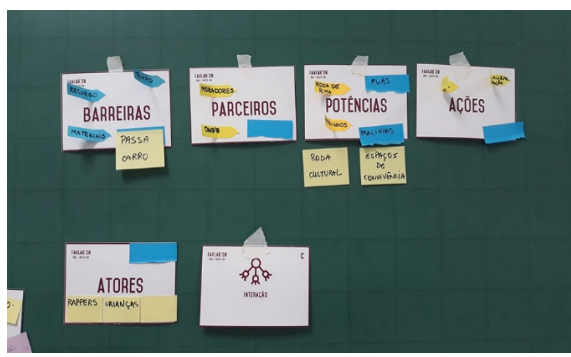

Figure 4: Example of cards set in use.

The second masterclass (2) Experimental urban laboratories and participatory tools introduced students to the concepts of co-creation, co-production, collective intelligence, tactical urbanism, network society, opensource, open-coding, sharing culture, citizen innovation, and maker culture. The tools provided included wiki platforms, digital fabrication tools, social media, open street maps, internet, and timeline.

After each lecture, students took a guided field trip to the favela. They were asked to have an eye towards the relationship between the territory observations and the concepts covered in the masterclass. Back to the studio, participants were asked to map the physical characteristics of the space (shapes and configurations), uses, appropriations, and also their intangible layers (memories, narratives, cultures, and complexities). Due to safety restrictions, students were prevented from taking pictures in some particular situations, and due to budget restrictions, they used an orthophoto printing. This phase was crucial for the participants to establish a link between themselves and the territory, which would be reflected in the final proposals.

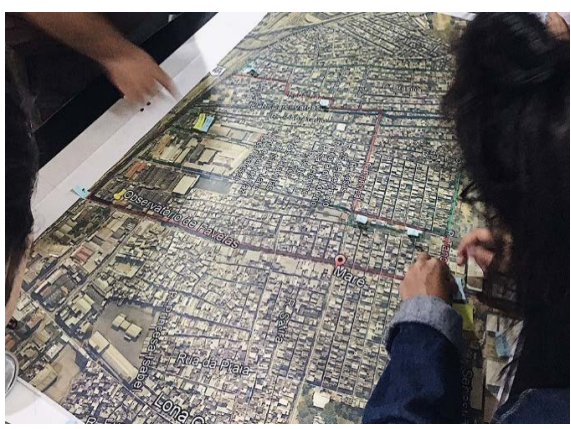

Figure 5: Workshop participants mapping the territory.
After this phase, students had sufficient theoretical background and local knowledge to move forward to the next phase, more focused on the technical aspects.

\section{Phase II - Technological knowledge sharing} (days 3 and 4 and 5)

Phase II was held at the university and started with the last masterclass, (3) An overview of digital processes in design and manufacturing. The lecture examined the following notions: peripheral technologies, parametric design, generative methods, agent-based design, interaction, and digital fabrication. The lecture contextualized the set of digital tools in which participants would be trained subsequently: parametric design, virtual reality, digital manufacturing, and prototyping.

Afterwards, the workshop proceeded to parametric modelling training with Rhinoceros and Grasshopper, interactive design classes with Arduino, and digital fabrication tooling. Architecture students and favela's participants attend six parametric design classes from the basics to intermediate level. The tutorials covered contouring, folding, sectioning, and panelling techniques. Regarding digital fabrication, participants experimented with 3D printing and laser cutting. The exercises were prepared considering local applicability and budget restrictions.

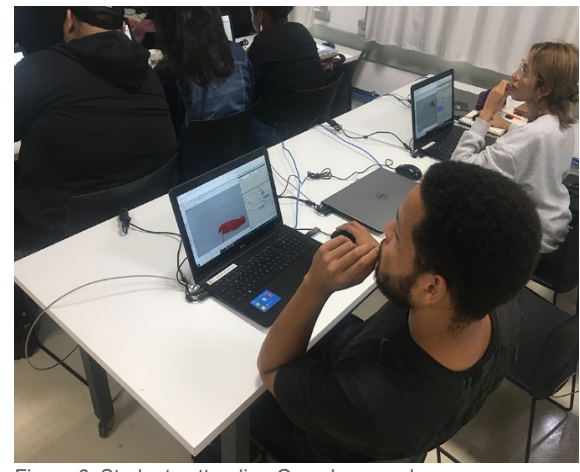

Figure 6: Students attending Grasshopper class.

\section{Phase III- Co-design}

(days 6, 7 and 8)

The co-design phase reinforced acquired knowledge from previous phases since students were asked to merge technical and theoretical expertise learned and materialize it into a co-designed product. The class was split into teams of three with different backgrounds, skills, and experiences to foster multidisciplinary collaboration in the proposals' development. The groups were stimulated to connect local partners and incorporate local creative agencies. By the end of the third day of the co-design phase, the teams exposed their ideas to the tutors and all attendees. This method ensured a non-hierarchical collectiveness quality to the designed outcomes. It also had an essential role in fostering knowledge sharing. For instance, one teammate from one group could possess the know-how to solve a specific problem from another group, and so on.

Students also used the set of cards as the proposals' conceptual guides and thinking maps. This approach facilitated the comprehension of meanings and social values that each step of the decision making of the design 
process would incorporate. This strategy was crucial to avoid solutions alienated from the context.

At the end of this phase, students and teachers voted for a proposal to be co-produced. The chosen project worked upon a popular game among children from Rio's favelas called 'golzinho' (little football goal). The game consists of kicking towards a simulated goalpost on the wall and hit as many goals as possible. The proposal aimed to increment the existing game by adding an interactive digital component. The interactive 'golzinho' consists of three targets equipped with impact sensors connected to an Arduino board. Once the player hits one target, a goal narration sound is triggered, and a led strip lights up. The intricate programming code considered a six minutes game. The group also proposed a goalpost scenario to be painted by the children. This strategy is twofold: it aims to incorporate the local kids in the co-production phase and to stimulate the sense of preservation of the toy among them.

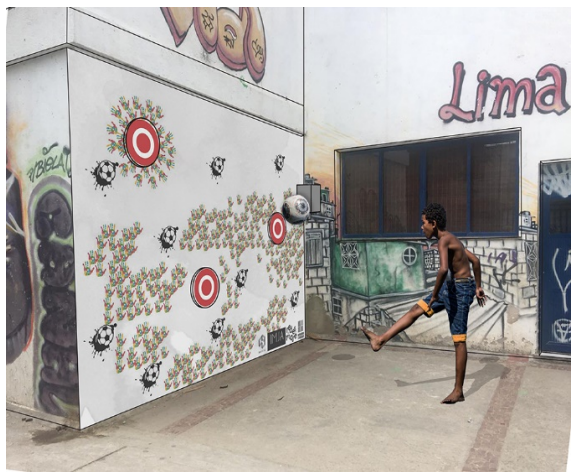

Figure 7: Intercative "golzinho" proposal.

Phase IV - Co-production

(days 9 and 10)

After defining which proposal would be implemented, the group was gathered into one big team with the common goal of co-producing the projects' ensemble parts. Students decided and self-declared which of the tasks they would engage in to set the game in place. The lists of assignments consisted of: (1) code programming; (2) Arduino prototyping; (3) targets' CNC milling; (4) electronic assemblage; (5) designing and laser cutting peripheral parts; (6) lighting assemblage, and (7) sound effects assemblage.

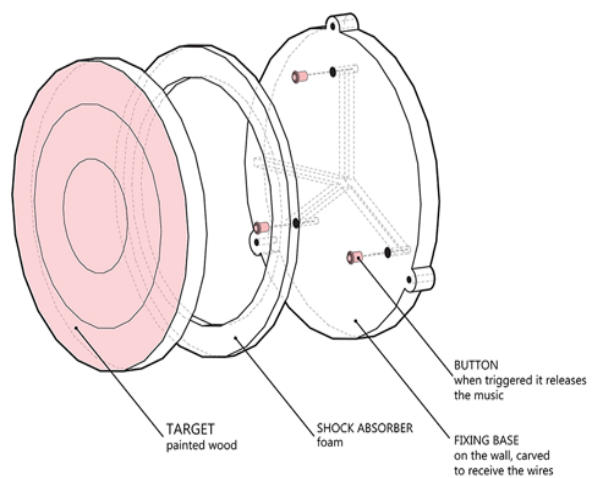

Figure 8: Intercative "golzinho" scheme.

\section{Phase V - Implementation}

The implementation phase was postponed for three weeks due to the disponibility issues of favela's leaders. The original schedule foresaw the game assembly by the endMarch. However, the date coincided with the outbreak of the Coronavirus crisis in Brazil and the beginning of the quarantine. The game assemblage was suspended until further notice. Nevertheless, it is expected to be installed in January 2021. Project updates are available on the website favlab.org.

\section{DISCUSSION}

The concepts, precedents, and practical experience exposed in this paper offers a broad range of discussion. We will focus on three main topics. The first one points to the social appropriation of digital technology, beginning with the question "what ought we do with our knowledge?" Contemporary architects possess specialized capabilities due to their growing knowledge and understanding of technological developments and their varying sociocultural milieu interactions. Technological capabilities do not determine our actions. Plus, architecture approximates to a problem-seeking and not a problem-solving discipline. It means that it is our call on how to address technology in architecture.

It leads us to the second point: how to establish social value in architecture? This question derived from the first one has been gaining significant expression in the last years. Indeed, after two digital turns (Carpo, 2017) and several technological stages and trends, formal manipulation has clearly dominated digital practice in architecture for the past decades. However, as societies have faced global and imminent challenges, such as climate change and growing urban poverty, the most explosive issues in contemporary society (Davis, 2006) seem unsustainable to avoid the debate on social value in digital architecture. Now is an opportune moment to discuss how architects and architecture can improve people's lives, explore the meaning and potential of social value, and inclusive design as an instrument of change in the built environment.

The third and last point is the powerful synergy that emerges from the relationship between formal and informal knowledge to address specific and context-appropriate questions to technology. As Richard Sennett (2012) stated, "better use of new technologies would focus more on coordination than on command", and that "technology might aid informal social relations rather than repress informality in the name of coherent control". He goes further: "informal social processes are the genius of the city - the source of innovation economically and the foundation of an arousing social life. Technology must be part of the process of giving the city that informal energy - and can do so if we think of our new technological tools as enabling the open systems of the city". We are tuned with Sennet, by exposing the beneficial interactions that can arise when digitally advanced institutions, such as universities or Fab Labs, provide access, and create collaborative processes within underprivileged urban areas residents. Social engagement does not have to be mundane, uninteresting, nor lacking high technology. At the same time, architects may use digital technology to embrace, empower, and resignify informality. Not to erase it in favour of canned solutions. 


\section{CONCLUSIONS}

Fab Labs potentialize reflective learning experiences that aim to explore new forms to produce knowledge. These labs' experimentative and collaborative environments offer diverse integrated ways to use digital technology in collaborative design processes in informal contexts. They also set a favourable atmosphere in which the university, professionals, institutions, and citizens can combine specialized and non-specialized knowledge, becoming more permeable to local complexities. The experience presented in this paper successfully departed from an immersive action in the territory towards an open and permanent platform of mutual collaboration. It also successfully indicated alternative paths for urban designers to act as process facilitators and how they can explore new tools that stimulate the collective creativity of everyone involved.

From an educational point of view, the adopted methodology proved to be adequate. The students' initial introduction to the territory before the digital tools tutorials was positive. Students had more time to assimilate concepts and to elaborate on complete territory-related design strategies. The community accepted the results exceptionally well. Finally, in this paper, we cherish inspiring architects toward a socially digital turn in architecture.

\section{ACKNOWLEDGEMENTS}

The authors thank the fourteen students ( Ariel Roque, Angélica Braga Sampaio, Bianca Naylor Rezende, Daniel Lineu, Gabriel Lemgruber, Gabriella Cardoso Fonseca, José Renato Erthal, Luisa Albuquerque Botelho, Marcella Cutrim, Paola Dargoni, Rhayssa Dandara Nogueira da Silva, Rosinaldo Lourenço, Thaís Alves do Nascimento, Thaís de Paula Soares), the tutors (Maíra Martins, Lucas Dominique, William Barbosa), the participation of Marcella de Signore. Special thanks for the Dean of CTCH/PUC-Rio Julio Diniz and PUC-Rio Department of Architecture for the moral and finantial support.

This work is partially funded by funds through FCT Fundação para a Ciência e Tecnologia, I.P., under the project FCT IDB/ 04466/ 2020.

Furthermore, the authors thank the Instituto Universitário de Lisboa and ISTAR-IUL, for their support.

\section{REFERENCES}

Carpo, M. (2017). The second digital turn: design beyond intelligence. MIT Press.

Castells, M. (2010). The Rise of the Network Society (2nd ed.). United Kingdom: Blackwell Publishing Ltd.

Center for Bits and Atoms (n.d.). Retrieved from https://fab.cba.mit.edu/

Claudel, M., Ratti, C. (2016) The City of Tomorrow, Yale University Press.

Concilio, G., Rizzo, F. (2016). Human Smart Cities. Rethinking the Interplay between Design and Planning. Springer. doi: 10.1007/978-3-319-33024-2

Davis, M. (2006). Planet of slums. Verso.

de Lange, M., de Waal, M. (2019) The Hackable City: Digital Media and Collaborative City-Making in the Network Society. Springer. doi: 10.1007/978-981-13-2694-3
Diez, T. (2012, 15 Oct). Personal Fabrication: Fab Labs as Platforms for Citizen-Based Innovation, from Microcontrollers to Cities. Nexus Network Journal. doi: 10.1007/s00004-0120131-7. Retrieved from https://link.springer.com/article/10.1007/s00004-012-0131-7

Ermacora, T., Bullivant, L. (2016). Recoded City: Co-creating Urban Futures. Routledge: New York.

Eychenne F., Neves, H. (2013). Fab Lab: a Vanguarda Da Nova Revolução Industrial. São Paulo: Editorial Fab Lab Brasil.

Garret, M. (2012). DIWO (Do-It-With-Others): Artistic co-creation as a decentralized method of peer empowerment in today's multitude. Retrieved from http://goo.gl/A1u0uf

Gershenfeld, N. (2005). Fab: The Coming Revolution on Your Desktop - From Personal Computers to Personal Fabrication. New York: Basic Books.

Gershenfeld, N. (2012, Nov/Dec). How to Make Almost Anything. The Digital Fabrication Revolution. Foreign Affairs Volume 91, Number 6, 42-57

Greenfield, A. (2013). Against Smart City. Amazon Media. Kindle edition.

Gershenfeld, N., Gershenfeld, A., \& Cutcher-Gershenfeld, J. (2017). Designing reality: How to survive and thrive in the third digital revolution. Basic Books.

Hummels, C. (2011) Teaching attitudes, skills, approaches, structure and tools. Open Design Now: Why Design Cannot Remain Exclusive. Amsterdam, The Netherlands: BIS publishers.

Kranzberg, M. (1986). Technology and History: "Kranzberg's Laws". Technology and culture, 27(3), 544-560.

Natividade, V. Dias, S. (2019). FavLabMaré Edition. eCAADe SIGraDi 2019. Proceedings of the 23th Conference of the Iberoamerican Society of Digital Graphics, Porto 9 - 13 September 2019, vol I pp. 349-358 Retrieved from https://ecaadesigradi2019.arq.up.pt/new/conferenceproceedings-available-for-download/

Ratti, C., \& Claudel, M. (2016). The city of tomorrow: Sensors, networks, hackers, and the future of urban life. Yale University Press.

Rifkin, J. (2011). The third industrial revolution: how lateral power is transforming energy, the economy, and the world. Macmillan.

Sá, I. (2015). Cidades de código aberto: por um urbanismo de segunda ordem. VIRUS, São Carlos, 10. Retrieved from http://www.nomads.usp.br/virus/virus10/?sec=4\&item=5\&lang $=p t$

Sassen, S. (2011). Open source Urbanism. New York: Domus Web. Retrieved from https://www.domusweb.it/en/oped/2011/06/29/open-source-urbanism.html

Sassen, S. (2012). Urbanising Technology. Retrieved from https://urbanage.Isecities.net/conferences/electric-citylondon-2012

Sennett, R. (2012). The stupefying smart city. Retrieved from https://urbanage.Isecities.net/conferences/electric-citylondon-2012

Schumacher, P. (2019). Social Performativity - Architecture's Contribution to Societal Progress. Published in: The Routledge Companion to Paradigms of Performativity in Design and Architecture: Using Time to Craft an Enduring, Resilient and Relevant Architecture, Ed. Mitra Kanaani, Routledge, Taylor \& Francis Group, New York \& London 2020.

Unwin, T. (2019). Digital Economies at Global Margins: A Warning from the Dark Tim Side. Digital Economies at Global Margins, 43.

Wisnik, G. (2018). Dentro do nevoeiro. Ubu Editora LTDA-ME. 